\title{
Diaconia e violência doméstica numa perspectiva histórica
}

\author{
Diaconia and domestic violence \\ in a historical perspective
}

Rubem Fonseca Flexa ${ }^{1}$.

Resumo: Este artigo objetiva analisar a história da diaconia na Igreja Primitiva, nos seus diversos viés. A diaconia é uma instituição divina e uma organização terrena constituída nos primórdios da igreja para viabilizar as necessidades básicas da comunidade carente e a prática da fraternidade. Nesse prisma, é possível também refletir sobre a violência doméstica, que não é só física e pessoal, mas psicossocial, material e assistencial. O Estado deve ser o primeiro a cumprir o seu papel constitucional na assistência social e garantia dos direitos individuais dos cidadãos. Combatendo assim, a miséria e a violência doméstica na sociedade.

Palav ras-chaves: Diaconia. Igreja Primitiva. Violência doméstica.

Abstract: This article aims to analy ze the history of diakonia in the Early Church, in its various biases. The diaconia is a divine institution and an earthly organization constituted in the beginnings of the church to make feasible the basic needs of the needy community and the practice of fraternity. In this perspective, it is also possible to reflect on domestic violence, which is not only physical and personal, but also psychosocial, material and care. The state must be the first to fulfill its constitutional role in social assistance and guarantee the individual rights of citizens. Combating this, the misery and domestic violence in society.

Artigo recebido em: 18 març. 2018 Aprovado em: 03 ago. 2018

1 Mestrando em Ciências das Religiões pela Faculdade Unida de Vitoria. Pós-Graduado em Assessoria de Comunicação e Mídias DigitaisFBN/Manaus. Pós-Graduado em Ciências Jurídicas e Dogmática JurídicaUFSC. Especialista em Direito do Trabalho -UNIVALI/Itajaí. Bacharel em Ciências Teológicas e Jornalismo - FBN/Manaus. Bacharel em Direito USF/ Bragança Paulista. Advogado, Jornalista e Pastor Evangélico. 
Key words: Diaconia. Primitive Church. Domestic violence.

\section{Introdução}

Como diz Severino Croatto "Para entender a linguagem religiosa (símbolo, mito, rito), é necessário partir da experiência do sagrado a que a própria linguagem quer comunicar. Do contrário, trabalha-se sobre termos sem o seu correlato real na vida." 20 objetivo deste trabalho é verificar a história da diaconia em seus diversos viés, desde o surgimento na Igreja Primitiva, como instituição social, e suas fases até a sociedade moderna. Averiguar as atividades desta instituição como é desenvolvida pela Igreja dos Primeiros Séculos até as Igrejas dos dias atuais³ ${ }^{3}$

Abordar a questão da violência doméstica urbana na sociedade e como a diaconia contribui com o necessitado. Para tanto, pretende-se definir o termo diaconia e fazer abordagem histórica da diaconia em suas diversas fases; em seguida falar da violência doméstica, não só a física e pessoal porém psicossocial, assistencial e material; representado pela classe de pessoas desempregadas, moradores de ruas, de viadutos e pontes, sem um lar e assistência adequada do Estado.

\section{Definição de diaconia}

A palavra diaconia é conhecida entre os cristãos, como serviço social da igreja, porém, vejamos uma definição para uma melhor compreensão do seu significado; o termo diaconia na lição de Elisabeth Schüssler Fiorenza, citada por Sissi Georg Rieff 4 , vem do grego diakonia e significa literalmente "servir à mesa" e foi traduzida por "serviço" ou "ministério". De acordo com o Dicionário do Novo Testamento Grego, de W. Taylor, mencionado por Andrades, a definição de diácono é:

2 CROATTO, José Severino. As linguagens da experiência religiosa. Uma introdução à fenomenologia da religião. São Paulo: Paulinas, 2001, p. 41. 3 A igreja cristã dos dias atuais, denominada nestetrabalho, tem significado como sendo a igreja cristã existente desde o período do início da Reforma Protestante, 31 de outubro de 1517 d. C., até os dias atuais. HURLBUT, Jesse Ly man. História da igreja cristã. Ed. Vida. p.141.

4 FIORENZA, Elisabeth Schüssler. Servir à mesa - reflexão sobre a diaconia a partir da teologia feminista crítica. Consilium. Petrópolis: 1988, $\mathrm{n}^{0} 218$, p.94-104.

5 ANDRADE, Claudionor Correa de. Manual do Diácono, $1^{\mathrm{a}}$ ed. Rio de Janeiro: CPAD, 1999, p.14. 
"Garçom, servo, administrador e ministro.” "No mesmo comentário, afirma que na Grécia Clássica, diácono era encarregado de levar as iguarias à mesa. Na Septuaginta, era os servos chamados de diáconos, porém, não desfrutavam da dignidade de que usufruíam seus homônimos do Novo Testamento, nem era incumbidos de exercer a tarefa básica destes: socorrer aos pobres e necessitados. Para "os judeus, era esse um cargo nada honroso."

A expressão dos Apóstolos, no livro de Atos, também coaduna com a definição de diaconia no seu original, "servir à mesa", conforme relato do livro sagrado "não é razoável que nós abandonemos a palavra de Deus para servir às mesas.”(At 6.1-2). O termo abandonar, expressado pelos Apóstolos, pode parecer forte, porém, no contexto, tem o sentido de deixar de dar atenção a pregação da Palavra de Deus para voltar a atenção com exclusividade aos carentes e necessitados de alimentos da igreja. Não quer dizer, com isto, que não seja importante a obra com os necessitados, e sim que outras pessoas poderiam fazer, com eficiência, mas que a pregação da Palavra de Deus teria prioridade, entre os Apóstolos, porque é o alimento da alma e não apenas do corpo.

\section{Diaconia como instituição}

Os lideres da Igreja Primitiva, no início, conviveram com Cristo e evidenciaram estima junto à comunidade religiosa. Tal posição foi mantida junto aos irmãos da época, porém, surge reclamações das viúvas helenistas sobre a distribuição de alimentos. Os Apóstolos resolveram esta questão escolhendo sete homens idôneos e de boa reputação para desempenhar a tarefa da diaconia. Surgindo assim a instituição e oficialização da diaconia na Igreja Primitiva, conforme relata o livro de Atos e comentário bíblico que esclarece os acontecimentos:

Os cristãos que falavam grego reclamaram que suas viúvas não eram tratas de forma justa. Talvez esse favoritismos não fosse intencional; a causa seria a barreira causada pelo idioma. Para corrigir a situação, os apóstolos constituíram sete homens responsáveis que falava grego como responsáveis pelo programa de distribuição de alimentos. Isto resolveu o problema e permitiu que os apóstolos 
mantivessem seu foco no ensino e na pregação das Boas Novas de Jesus. 6

A diaconia, antes da oficialização histórica com os Apóstolos, já existia como atividade informal de distribuição de alimentos aos necessitados. Jesus foi o primeiro a deixar lições significativas nesta área e os Apóstolos entenderam a lição do Mestre: "amar ao próximo como a si mesmo" (Mt 22.37-40) e não olvidaram em colocar na prática a fraternidade entre os irmãos carentes, visto que descobriram o valor e a importância desta obra. Assim a diaconia, na sua origem, é uma instituição divina de servir à comunidade, as pessoas carentes.

As igrejas cristãs ainda conservam essa prática, e outras a diaconia deixa muito a desejar, pela visão trocada do "ser" pelo "ter", com acumulação de bens materiais sem beneficiar o próximo. Os diáconos da Igreja Primitiva realizaram essa obra filantrópica e muitos atualmente, ainda realizam, com louvável e merecida dedicação, por tratar-se de uma obra de realização pessoal quando feita com amor apreço.

\section{Pressupostos da diaconia}

A história apresenta sempre pressupostos como atos preparatórios antes da realização de um grande acontecimento. Tais atos se fazem necessários à compreensão da trajetória de um acontecimento histórico, nos determinados períodos; como exemplo o dilúvio, anunciado a Noé bem antes de sua realização, e só concretizado depois da preparação da Arca construída, 100 anos depois, como relata o Livro do Genesis ( $\mathrm{Gn} 5.32$; 6.13,14; 7.6); o anúncio à Abrão da entrada e saída do povo Hebreu do Egito; evento previsto 400 anos antes(Gn 15.13,14); o nascimento de Jesus, anunciado pelo Profeta Isaias (Is 9.6), 730 anos antes da sua realização (Mt 1.18, Lc 2), fatos exem plificativos que elucidam os pressupostos de eventos que marcaram a história bíblica.

Temos fatos relatados acerca de Jesus como "o Cordeiro de Deus," morto, simbolicamente, antes da fundação do mundo. É evidente que a crucificação, na terra, seria uma manifestação real do simbolismo revelado bem antes de acontecer. Nesse sentido, os pressupostos do plano de Deus da redenção do homem, foram

6 BIBLIA SAGRADA. Português. Bíblia de estudo aplicação pessoal. Tradução de João Ferreira de Almeida Versão Revista e Corrigida. Rio de Janeiro: Sociedade Bíblica do Brasil, CPAD, 1995. P. 1488. 
previstos bem antes da sua realização na terra; como relata o Apóstolo João: "[...]...cujos nomes não estão escritos no livro da vida do Cordeiro que foi morto desde a fundação do mundo." (Ap 13. 8 ).

$\mathrm{Na}$ Primeira Epístola de São Pedro é relatado também esse assunto que se refere a Cristo: "O qual, na verdade, em outro tempo foi conhecido, ainda antes da fundação do mundo, mas manifestado nestes últimos tempos por amor de vós;" (I Pe 1. 20); seguido também pelo Apóstolo São Paulo que expressa: "Como também nos elegeu nele antes da fundação do mundo, para que fôssemos santos e irrepreensíveis diante dele em amor;" (Ef 1. 4); os exemplos citados trazem uma compreensão dos pressupostos e simbolismos da história bíblica, como "o Cordeiro" representado por um animal, que serve de sacrifício no lugar do homem, antes da criação do mundo e da sua realização, nos templos judaicos e da morte de Cristo na terra; evitando a morte do homem por causa do pecado de Adão.

$\mathrm{Na}$ história, principalmente da Igreja, há os grandes acontecimentos que marcaram o início e o fim de uma Era, de um Período, de uma Época, conforme ensinamento de Jesse Lyman Hurlbut:

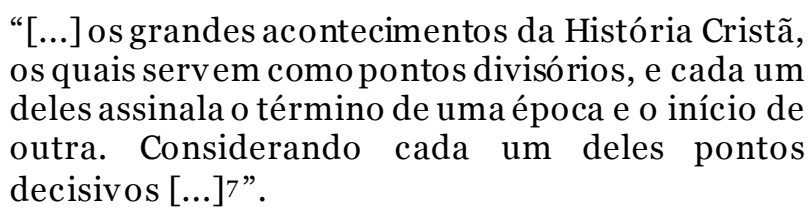

A Era do Cristianismo ficou evidenciada no evento da vinda de Jesus à terra que dividiu o tempo em duas Eras: Antes e Depois de Cristo, (a.C. e d.C.), como existe atualmente. A diaconia tem os seus pressupostos de historicidade, às vezes pouco conhecido; como o amor divino voltado exclusivamente para o ser humano. Pode ser visto a preocupação do Criador na preparação da sobrevivência do homem na terra.

Historicamente, isto vem de longas datas, conhecida como "eterno passado," época que não se tem revelada a noção real dos acontecimentos. Sabe-se apenas que o tempo de Deus é revelado por eventos ( Kairós), como o Dilúvio, (Gn 6.11-22), o Êxodo de Israel do Egito, (Ex 3.1-10), a Vinda de Cristo à terra para morrer na Cruz do Calvário,(Is 53.1-7), o Arrebatamento da Igreja, (Jo 14.1-4); a prisão de Satanás (Ap 20.1), o Reino Milenar de Cristo na terra (Ap 20.6); a destruição de Satanás (Ap 20.7); o Juízo Final (Ap 20.11); a nova

7 HURLBUT, Jesse Lyman. História da igreja cristã. Ed. Vida. p.15. 
Jerusalém, o novo céu e a nova terra (Ap 21.1-5); sendo diferente do tempo do homem (Khronos), revelado pelo tempo cronológico; principalmente, em relação a época de sua realização, nos desígnios de Deus, como é propício citar o pensamento de Santo Agostinho:

Nenhuns tempos Vos são coeternos porque Vós permaneceis imutável, e se os tempos assim permanecessem,já não seriam tempos. Que é, pois, o tempo?[...]Vós sois, antes de todos os tempos, o eterno Criador de todos os tempos. Estes não podem ser coeternos convosco, nem nenhumas outras criaturas, ainda que haja algumas que preexistem aos tempos. (Santo Agostinho, Confissões, Livro XI, §14 e 30)

O homem por natureza é uma criatura paradoxal, um ser diferente. Não é explicado facilmente pela ciência; pois há algo imanente, da eternidade do Criador em si, que se torna um ser totalmente diferente dos animais e seres angelicais criados. Desse modo, o homem se torna o centro das atenção de estudos das religiões, das ciências humanas e das demais ciências abrangentes como explica Wilhelm Dilthey:

[...] Ao lado das ciências naturais, e partindo das tarefas da própria vida, desenvolveu-se por si mesmo e de maneira espontânea um grupo de conhecimentos ligados uns aos outros por meio da comunhão de seu objeto. Tais ciências são a história, as ciências econômicas e jurídica e a ciência do estado, a ciência da religião, o estudo da literatura e da poesia, da arquitetura e da música, das visões do mundo dos sistemas filosóficos e, por fim, a psicologia. Todas essas ciências descrevem, narram, julgam e formam conceitos e teorias em relação ao mesmo grande fato: a espécie humana. ${ }^{8}$

A história da criação revela o trabalho que Deus fez em favor do homem para disponibilizar um lugar propício para a sua sobrevivência. A diaconia está representa nesse serviço, como é relatado pelo Livro do Genesis (Gn Cap 1 e 2). Nesse

8 DILTHEY, Wilhelm. A construção do mundo histórico nas ciências humanas. São Paulo: Editora UNESP, 2010, p. 19. 
caso, a diaconia se apresenta como atividade divina, evidenciada na vontade de fazer o bem ao ser humano.

\section{Natureza e extensão da diaconia}

A natureza da diaconia é divina pois instituída através do amor de Deus e terrena por ser implantada na igreja por homens da sociedade. A diaconia representa uma atividade divina e humana mais o serviço é sempre voltado para o homem. Provém de Deus revelado pelos Dez Mandamentos "amar ao próximo como a si mesmo" instituída por Cristo.

Apesar da última função referida, servi ao homem, ter levado milhões de anos para ser concretizada, por ser uma criação posteriori a dos anjos que o serviriam na sua existência, conforme comentário do Livro de Gênesis

Muitas pessoas crêem que a natureza, o sol, a lua, as estrelas, e os seres humanos nunca tiveram um princípio; que há um ciclo eterno e inacabável de nascimento, vida e morte, que se repete constantemente. Crêem que tal ciclo eterno jamais teve início e jamais terá fim. Sempre existiu e sempre existirá9.

Continuando, nesse mesmo comentário, pondera:

A Bíblia nos ensina algo diferente. Ensina-nos que houve um tempo em que o mundo não existia. $O$ Deus da Bíblia não é uma força ou um princípio absoluto e desconhecido. É, antes, uma pesso a. Ele conhece e pensa; tem emoções; ama. Esse Deus decidiu revelar-se criando o mundo. E com essa decisão sua, o mundo teve início ${ }^{10}$.

9 BIBLIA, Português. Bíblia devocional de estudo. Tradução de João Ferreira de Almeida. Versão Revista

e Corrigida. Rio de Janeiro: Imprensa Brasileira. 1987. Genesis Cap. 1-3.

10 BIBLIA, Português. Bíblia devocional de estudo. Tradução de João Ferreira de Almeida. Versão Revista

e Corrigida. Rio de Janeiro: Imprensa Brasileira. 1987. Genesis Cap. 1-3. 
Comenta ainda sobre a criação quando Deus criou o mundo o fez bom, perfeito e acabado:

Quando Deus criou o mundo, criou bom. Ao ler o primeiro capítulo de Gênesis, anote quantas vezes o autor repete o pequeno refrão: "Eviu Deus que era bom”. Isto não somente signific a que não havia pecado no que Deus fez, mas que também tudo funcionava perfeitamente. Não havia tormentas, nem fome. Não havia destruição no mundo perfeito que Deus fizera. No relato da criação do mundo, vemos a forma precisa e cuidadosa com que Deus completou a sua criação. ${ }^{11}$

O propósito de Deus é preparar os elementos, naturais e celestiais, para o estabelecimento do homem na terra. Nessa lição temos que Deus, no eterno passado, quando o homem ainda não existia, planejou a criação dos seres celestiais anjos, arcanjos, querubins, como agentes de serviços ao homem e preparou a terra para que esse viesse habitar. Dessa maneira a diaconia é o principal objeto do Criador para beneficiar o homem.

A diaconia na perspectiva histórica-existencial focaliza o passado, o presente e o futuro do homem. Tem-se visão panorâmica da realidade quando Deus cria a hierarquia angelical e distribui poderes e funções aos anjos e arcanjos, para servir. Ao analisar o projeto de Deus para a humanidade, comenta Carlos Pinheiro Queiroz:

No princípio Deus criou o céu e a terra." Assim começa a descrição da história da humanidade no Gênesis. O escritor, mesmo vivendo num contexto político, social e econômico já em processo de destruição, consegue vislumbrar o ideal de Deus na criação. Os capítulos 1 e 2 podem funcionar tanto como ponto de partida como ponto de chegada, do propósito de Deus para a humanidade. Deus surge no relato como autor da criação. É apresentado como ser soberano, inteligente, pairando sobre 
vácuo e de maneira majestosa; do nada cria sobrenaturalmente todas as coisas. E o faz com beleza e perfeição. ${ }^{12}$

Deste modo, a diaconia é o elemento da visão divina para servir a humanidade, tal finalidade não pode ser desvirtuada, para não tirar o brilho desta obra, pois a natureza da diaconia está diretamente relacionada com a atividade divina, com sua extensão na terra, conforme ensina a lição de Naylor,
A natureza do diaconato exige mais do que indicação e eleição pela igreja. O diaconato não é um ofício que se alcance, nem propriamente uma honra ou distinção que se receba. [...] O diácono é escolhido para servir. Assim, ele deve consagrar toda a sua vida a esse serviço e a tudo quanto com ele se relacione. [...] O diaconato, à luz do Novo Testamento, é um posto de serviço e não de autoridade ou mandonismo. Aceito tal ofício, o diácono perde o direito a quaisquer privilégios pessoais ou individualistas ${ }^{13}$.

A histórica da diaconia é marco visionário que abrange diversas fases da sua existência; têm-se a visão cosmológica quando busca investigar a origem e finalidade dos mundos tanto animal, vegetal ou mineral, os quais foram criados para suprir a necessidade do homem. No plano terreno a diaconia atinge a forma de organização de atividade e ministério do serviço ao necessitado.

A norma de Deus é a do amor vinculada ao próximo (Êxodo 20). Jesus, em seu ministério terreno, reforça esta premissa quando um jovem faz a pergunta: "Mestre, qual é o grande mandamento na lei? A resposta de Jesus é de quem tem autoridade no assunto:

Respondeu-lhe Jesus: Amarás o Senhor teu Deus de todo o teu coração, de toda a tua alma, e de odo o

12 QUEIROZ, Carlos Pinheiro. Eles herdarão a terra. Encontro publicações. Curitiba: 1998, p.25.

${ }^{13}$ NAY LOR, Robert E. O diácono na bíblia.7.ed.Rio de Janeiro:JUERP, 1992. p.59-60 
teu entendimento. Este é o grande e primeiro andamento. O segundo, semelhante a este é: Amarás ao teu próximo como a ti mesmo. Destes dois mandamento dependem toda a lei e os profetas." (Mt 22).

Para Fletcher, Jesus resumiu os dez mandamentos no amor. Ele falou primeiro do amor a Deus; depois, do amor ao homem. Essas declarações, disse ele, resumem todos os Dez Mandamentos e tudo quanto os profetas ensinaram. O ser humano, como criatura provinda das mãos de Deus, fomenta questões da mais alta relevância, quando se refere ao trinômio denominado de corpo, alma e espírito, representações, estas, em sua essência, pela trindade divina: pai, filho e espírito santo. Assim, como os elementos essenciais existentes na natureza terra, água e fogo, os quais obedecem uma ordem natural e divina.

A diaconia é revelada também como norma divina dada aos homens para servir ao próximo, é uma ordenança: "amai ao próximo como a si mesmo". Uma norma ligada intrinsecamente ao ser humano.

A proposta diaconal de Jesus, vivida e seguida pelas primeiras comunidade cristãs, considera o ser humano em todas as suas dimensões. O ministério de Jesus tem vários aspectos. A diaconia é um destes aspectos da fé cristã que a igreja procura viver como tarefa atribuída e deixada pelo próprio Cristo. No livro de João (Jo 13.15), Jesus diz: "[..]. eu dei o exemplo para que vocês façam o que eu vos fiz”. No livro de Atos dos Apóstolos (At 2.42) lemos: “[...] e todos continuavam firmes, seguindo os ensinamentos dos apóstolos, vivendo em amor cristão, partindo o pão juntos e fazendo orações". Cristo foi chamado de "servo" (Is.42.1) que, no original, significa diácono.

Segundo o comentário de Fleming comentando sobre Jesus como servo:

"O tipo bíblico de Cristo como servo foi cumprido na vida e obra de Jesus. Uma das passagens mais maravilhosas e impressionantes das Escrituras a esse respeito é Filipenses 2:3-8, que descreve a auto-humilhação do Salvador. O texto apresenta algumas das mais profundas verdades bíblicas a respeito da divindade e humanidade de Cristo. A intenção de Paulo ao expressar essas verdades não 
era primordialmente teológica, mas prática. Exortava os crentes filipenses a renunciar o egoísmo, e a ver as outras pessoas como sendo mais importantes do que os próprios destinatários de sua carta.[...]14."

\section{Para Rodolfo Gaede Neto fazendo comentário sobre a diaconia:}

Um dos textos bíblicos mais importantes para a fundamentação teológica da diaconia é o de Marcos 10.43-45. Trata-se da reação de Jesus ao pedido de dois discípulos, que queriam garantir a ocupação do seu lado direito e do seu lado esquerdo, quando ele se assentasse no trono do seu reinado em Jerusalém. A resposta de Jesus é um ensinamento à comunidade que o seguia. E o conteúdo desse ensinamento tem um caráter diaconal. Temos, portanto, neste texto, um posicionamento do próprio Jesus com respeito à diaconia comunitária. Jesus percebe que os discípulos estão obcecados pelas formas de organização da sociedade em que vivem. Nesta, os governantes ex ercem o poder de modo autoritário, de cima para baixo, oprimindo e explorando seus súditos. No seu ensinamento, Jesus esclarece que na comunidade de seus seguidores e suas seguidoras não é assim ${ }^{15}$.

\section{O ensinamento de Jesus mostra inversão de realidade, como explica Rodolfo Gaede Neto:}

O que Jesus ordena à comunidade de suas seguidoras e seus seguidores é, na verdade, uma constante e radical inversão em relação aos valores vigentes na sociedade da época: a pessoa que quer ser grande é pequena; aquela que quer ser a primeira é a última; a que quer ser servida, sirva; valendo também o inverso: os últimos serão os primeiros (Mateus 20.16), as pequenas crianças ocupam o centro das atenções (Marcos 9.36), os servos são servidos (João 13.4-5), as pessoas cegas,

\footnotetext{
${ }^{14}$ FLEMING, 1995, p.33

${ }^{15}$ NETO, 2001,p.10-11
} 
coxas, pobres e aleijadas das ruas e becos são as convidadas para a grande ceia (Lucas 14.2'1).[... ${ }^{16}$.

A instituição da diaconia na Igreja está relacionada com o aumento do número de seus adeptos. Há murmuração no tratamento das viúvas de origens helenistas em relação às viúvas judaicas por falta de assistência material, relatado em Atos 6.1:
“Ora, naqueles dias, multiplicando-se os números dos discípulos, houve murmuração dos helenistas contra os hebreus, porque as viúvas deles estavam sendo esquecidas na sua distribuição diária”.17

Devemos entender a contextualização do momento histórico para uma melhor compreensão do texto, como ensina Júlio Zabatiero, (2012, p. 53). Entende-se que os membros da Comunidade Primitiva havia comunhão entre si com controle diário na distribuição dos alimentos. É bem verdade, que o aumento dos discípulos foi vertiginoso, razão da falta de comunicação com o idioma grego entre os hebreus. Entretanto a diaconia na Igreja Primitiva cumpriu o seu dever social com a sociedade da época, o que serve de lição para os dias atuais.

\section{Violência doméstica urbana}

A história revela que a violência doméstica vem de longas datas. A primeira violência familiar vem de onde não deveria vir; da primeira família do mundo, de Adão e Eva. Caim e Abel, foram objetos da primeira violência doméstica que se tem conhecimento. Caim cometeu o primeiro homicídio, matou Abel, seu irmão. Sobrevindo de Caim a geração de violência, no período antediluviano, conforme relata o Livro de Genesis (Gn 4.8-10); que segundo comentário bíblico dessa referência, foi decorrente do erro de seus pais:

Este é o primeiro assassinato - uma vida tirada pelo derramamento de sangue humano. O sangue representa a vida (Lv 17.10-14). Se o sangue foi

\footnotetext{
${ }^{16}$ NETO, 2001,p.11

17 BIBLIA SA GRADA, Português. Antigo e novo testamento.Traduzida em português por João FerreiradeAlmeida, edição Revista e Atualizada. Rio de Janeiro: Sociedade Bíblica do Brasil. CPAD, 1983, p.1106.
} 
tirado de uma criatura vivente, esta morrerá. Somente Deus pode tirar a vida, pois foi Ele quem a criou. A descendência de Adão e Eva trouxe o pecado para a raça humana. [...] O simples ato da desobediência degenerou-se rapidamente em violento assassinato. Adão e Eva agiram apenas contra Deus, mas Caim agiu contra Deus e outras pessoas. ${ }^{18}$

$\mathrm{Na}$ realidade, a violência, doméstica ou outra denominação, representa um mal na sociedade; pois atinge diretamente o ser humano e até o patrimônio público. A história do homem, desde o princípio, é recheada de violência.

Segundo a lição de Norberto Bobbio, defende o ponto de vista que "os direitos do homem, por mais fundamentais que sejam, são direitos históricos", o homem, no seu contexto histórico, tem sido mal compreendido, pois, para alcançar os direitos fundamentais, é necessário empreender lutas contra poder e oligarquias humanas.

À luz dessas ponderações, não se pode negar que o homem, como ser humano, tem sido objeto de estudos de muitas gerações, sem, contudo, obter uma compreensão completa e hegemônica de sua essência e dos males que lhe aflige. Muitos esforços se olvidaram nesse sentido, permanecendo a incógnita da imprevisibilidade do ser humano. Gottfried Brakermeier, destaca que o ser humano é um misto de anjo e fera, de coisa insignificante e preciosidade, de imagem de Deus e do demônio. Sem Deus o que seria? Já o autor do Salmo 8 se espanta com a pequenez do ser humano no universo e com a glória de que Deus, ainda assim, o coroou"19. Esta misteriosidade humana, só explicada pelo lado da espiritualidade.

O homem, no convívio social, é um ser paradoxal. É valorizado por um e desprezado por outro, inclusive por si próprio, principalmente, quando se trata de valores axiológicos, expressados pelo grupo de convivência. Na realidade, constata-se os extremos do ser humano como ensina:

O ser humano é um ser contraditório. É dotado da mais alta dignidade e, simultaneamente, dela se privou. Écapaz de admiráveis proezas, benefícios, obras culturais. E, todavia, não deix a de assustar

18 BÍBLIA, Português. Bíblia de estudo aplicação pessoal: Antigo e Novo Testamento.Tradução de João Ferreira de Almeida. Edição rev. e corrigida no Brasil. Rio de Janeiro: Sociedade Bíblica do Brasil, CPAD, 1995, p.12.

${ }^{19}$ BRA KERMEIER, 2002, p.47 
por sua crueldade e pela proporção de seus crimes. Vive jogando sua dignidade na lama e ameaça a de outros, reduzindo-os a peças na guerra pela sobrevivência ${ }^{20}$.

A sociedade brasileira vivencia momento que compromete a segurança e tranquilidade das pessoas física, psíquica, financeira, social, religiosa, familiar entre outras. O Estado Democrático de Direito é comprometido, pelo péssimo desempenho dos poderes e instituições constituídas, como se vê nos dias atuais. Mesmo existindo uma das mais brilhantes declarações de direitos e garantias constitucionais, como a Carta Magna de 1988, o país vive no desprestígio da Justiça pelos mais comezinhos direitos individuais, pela morosidade processual nas demandas sociais.

\section{Conclusão}

Deste modo, conclui-se que a diaconia é uma instituição divina que foi instituída pelo Criador desde os tempos remotos, no eterno passado, com exclusivo propósito de beneficiar o homem que seria criado por ocasião de todas as coisas. Foi instalada pela Igreja Primitiva, como organização social, voltada para o "amar ao próximo". Esta instituição fomenta o combate a fome, a miséria e o desequilíbrio social dos menos favorecidos.

A diaconia tem suas raízes milenar que é exercida por quem tem o amor e fraternidade. Serve para representar uma comunidade fraterna, justa e igualitária. O serviço diaconal bem instalado e representado por pessoas sérias, com organizações comprometidas com a qualidade de vida de seus compatriotas, como a Igreja Primitiva, ajuda a combater a violência doméstica, a fome, a miséria psicossocial e material de cidadãos desempregadas, doentes, sem teto e sem assistência governamental.

O Estado não pode deixar de promover politicas sociais sérias voltadas para a população carente assegurando estabilidade e equilíbrio social. O Estado deve ser o primeiro a cumprir o papel constitucional na assistência social e garantia dos direitos individuais dos cidadãos. O modelo que deve adotar é o da solidariedade diaconal, do amor ao próximo como a si mesmo para alcançar uma sociedade mais justa, fraterna e igualitária. 


\section{Referências}

AGOSTINHO, S. O Homem e o Tempo. In: confissões. 10. Ed. Porto: Livraria Apostolado da Imprensa, 1981.

BEULKE, Gisela. Diaconia em situação de fronteira: um exemplo chamado balsas. São Leopoldo: Sinodal: Centro de Estudos Bíblico, 2001.

BÍBLIA, Português. Bíblia de estudo aplicação pessoal: Antigo e Novo Testamento. Tradução de João Ferreira de Almeida. Edição rev. e corrigida no Brasil. Rio de Janeiro: Sociedade Bíblica do Brasil, CPAD, 1995.

BIBLIA, Português. Bíblia devocional de estudo. Tradução de João Ferreira de Almeida. Versão Revista e Corrigida. Rio de Janeiro: Imprensa Brasileira,1987.

BIBLIA, Português. Antigo e novo testamento. Traduzida por João Ferreira de Almeida, edição Revista e Atualizada. Rio de Janeiro: Sociedade Bíblica do Brasil, CPAD, 1983.

BOBBIO, Norberto. A era dos direitos. Rio de Janeiro: Editora Campus. 1992.

BRAKEMEIER, Gottfried. O ser humano em busca de identidade: Contribuições para uma antropologia teológica. São Leopoldo/São Paulo: Editora Sinodal/Paulus. 2002.

CASTRO, Emílio. Servos livres: missão e unidade na perspectiva do reino. Tradução de Maria C. Hahn. Rio de Janeiro: CID. Editora. 1986.

CESAREIA, Eusébio de. História da igreja. 1. ed. Rio de Janeiro: Casa Publicadora das Assembléias de Deus, 1999.

ERDMAN, Charles. Atos dos apóstolos. Tradução de D. A. M. São Paulo: Casa Editora Presbiteriana, 1960.

HURLBUT, Jesse Lyman. História da igreja cristã. Trad. Editora Vida. Flórida: Editora Vida, Deerfield, 1979.

NAY LOR, Robert E. O diácono na bíblia.7.ed.Rio de Janeiro:JUERP, 1992.178p 
NIEBUHR, H. Richard. As origens sociais das denominações cristãs. Tradução de Antônio Gouvêa Mendonça. São Paulo: Traço a traço editorial, 1992.

NORDSTO KKE, Kjell (Org.). A diaconia em perspectiva bíblica e histórica. Tradução de Werner Fuchs. São Leopoldo, RS: Sinodal: Centro de Estudos Bíblico, 2003. 304 p.

MARROU, Henrilrenee. Teologia da história. Tradução de Roberto Leal Ferreira. Petrópolis: Editora Vozes, 1989.

TUECHLE, Hermann; BIHLMEYER, Karl. História da igreja: Antiguidade cristã. Volume primeiro. Edições paulinas. Trad. Pe. Ebion de Lima. São Paulo: Pia sociedade de São Paulo, 1964.

ZABATI ERO, Júlio. Para uma Teologia Pública. $2^{\mathrm{a}}$. Edição. São Paulo: Fonte Editorial, Faculdade Unida, 2,011. 